\title{
Demographic Study of Gujjars of Delhi II. Reproductive Profile and Mortality Levels
}

\author{
Shweta Dabral and S.L. Malik \\ Department of Anthropology, University of Delhi, Delhi 110 007, India
}

KEYWORDS Reproductive Profile. Fertility. Mortality. Amenorrhoea.

\begin{abstract}
Fertility is a major counteracting force to population attrition from mortality and therefore, has a significant impact as an expansionary force in population dynamics. While mortality, on the other hand, checks the unlimited growth of population and regulates the distribution of individuals in different age groups. It is well known that increasing birth rates cause exposure to several social problems like crisis of minimum needs for survival and subsistence which includes scarcity of food and land, poverty, unemployment, illiteracy, etc. Information on fertility and mortality is relevant both to demographic assessment of the population and to assessment of health policies and programmes. Keeping this in mind, the present study was conducted among Hindu Gujjars of Delhi. The data for present study was collected by interviewing ever-married Gujjar women aged 15-49 years from a sample of 558 households. Fertility among Gujjars is higher than all Delhi population. Gujjar women are by and large reproductively active during prime childbearing ages of 20-29 years. Gujjar women tend to marry early and there is still a fair amount of fertility at very younger ages. Majority of pregnancies resulted in live births. For over three children born, around ninety percent are surviving. Infant and child mortality is relatively higher in groups where fertility is higher. The mean duration of postpartum amenorrhoea is 4.9 months. Mean age at menarche is 13.99 years while mean menopausal age is 44.06 years. Though IMR is lower among Gujjars, but overall mortality (CDR) is slightly higher than all Delhi population with respiratory disorder being the primary cause of death.
\end{abstract}

\section{INTRODUCTION}

Human fertility is responsible for the biological replacement and maintenance of the human species. In fact, the fertility is a major counteracting force to population attrition from mortality and therefore, has a significant impact as an expansionary force in population dynamics. Fertility may be defined as the actual reproductive performance of a woman or a group of women (Thompson and Lewis, 1965). However, the phase of actual reproductive performance is contented in terms of the physiological potential of a woman to conceive and bear children. This phase is termed as the fecund period, which has two extremes, viz., menarche and menopause. In demographic studies, the reproductive span i.e., the child bearing period of women is usually taken to as between 15 to 49 years of age. Thus, a fecund woman may or may not be fertile but a fertile woman must be fecund. The main events or phenomenon associated with fertility are age at menarche, age at marriage and age at menopause.

There is a wide variation in menarcheal age (I.C.M.R., 1972; Pawson, 1976; Malik and Hauspie, 1986). Many factors including genetic,

Address Correspondence: Dr. S. L. Malik, Professor Department of Anthropology, University of Delhi, Delhi 110 007, India

E-mail: slmalik@rediffmail.com nutrition and socioeconomic conditions influence age at menarche (Eveleth and Tanner, 1976; Bhasin, V., 1990; Bhasin and Nag, 2002a). Genetics perhaps sets the boundaries, but environment dictates how one falls within these limits. Simi-larly, Menopause is influenced by nutrition, genetics, socioeconomic conditions, climate, smoking habit, drugs and contraceptives (ICMR, 1998; Frisch and McArthur, 1974; Beall, 1983). The relationship between age at marriage and fertility is well known (Maudlin and Berelson, 1978; Nag, 1982; Pandey and Talwar, 1987). As age at cohabitation (i.e., age at consummation of marriage) determines the reproductive life span of a woman and has a direct bearing on fertility, it is one of the important aspects with regards to fertility (Maudlin and Berelson, 1978; Nag, 1982; Chaudhury, 1984). It is found that a later age at marriage reduces fertility (Agarwala, 1967; Durch, 1980; Yadav and Badari, 1997). Educational level, economic status, religious attitudes, women's work participation, etc are other factors, affecting fertility (RGI-fertility survey, 1971; Basu et al., 1988; Bhasin,V., 1990; Elamin and Bhuyan, 1999, Pandey et al., 2000; Bhasin and Nag, 2002b), in addition to, conception control practices and attitudes, (Bhuyan and Ahmed, 1984).

The most striking demographic event in the past few decades has been the unprecedented 
increase in the population, particularly in the developing countries, such as India, primarily due to the remarkable fall in mortality. There can be little doubt that the massive investments in health, sanitation, water supply, and other associated sectors have directly contributed to decline in the mortality rates (Preston, 1978; Kshatriya et al, 1997; Verma, 2002). The study of mortality is useful for analyzing current demographic conditions as well as for determining the prospects of potential changes in mortality condition of the future. The study of infant mortality is significant, especially because mortality during the first year of life is invariably high for all countries, irrespective of whether the overall levels of mortality are high or low. Infant mortality rate is not only a reliable indicator of health status and well being of the children but it is also an indicator of socioeconomic development of the population. In India, low birth weight is one of the major causes for infant mortality as this increases the susceptibility to infections. Diarrhoea and Acute respiratory infections particularly pneumonia are the other major causes (RGI, 1997; NIHFW report 1999-2000).

The present paper is second in the series of research articles dealing with various aspects of Gujjars of Delhi. In the paper, an attempt has been made to assess fertility of Hindu Gujjars of Delhi. It aims at estimating various fertility measures besides evaluating the reproductive profiles of Gujjar women, including age at menarche, age at menopause and duration of postpartum amenorrhea, along with the estimation of various mortality rates.

\section{MATERIAL AND METHODS}

The present study was conducted among Hindu Gujjars residing in Delhi. Five Gujjar predominated villages selected at random, were visited during different months of the year 2002 . The data was collected from ever-married Gujjar women aged 15-49 years from a sample of 558 households using interview schedule. The Interview Schedule consisted questions on household identification, ego's name, age, etc., besides questions related to reproductive profile. The Household Schedule was also used to collect information on all the live births and deaths that took place within the last one year in the household. (For details see Dabral and Malik, 2004a) The data collected was statistically treated, using descriptive statistics. In some cases age could not be appropriately assessed due to misstatement of age especially by older women who tend to understate their true ages. There are chances of underreporting in some cases about data on reproductive wastage.

The age-wise distribution of the respondents is shown in Table 1. A look at the general characteristics of the respondents reflects that nearly all the respondents are currently married (97.1 percent) while, the remaining females are widowed. No woman is either divorced or separated. About one-third of the respondents are illiterate while only about one-ninth have completed high school. A small proportion of women are graduate and above. Analysis of work status of the respondents reflects that almost cent percent are not working and are engaged in household activities that includes expanded domestic work like preparation of cow dung cakes, etc. All these reflect the present overall status of Gujjar women in Delhi.

\section{RESULTS AND DISCUSSION}

Current Fertility Levels: The evaluation of fertility levels in Gujjars on the basis of measures like Crude Birth Rate (CBR), General Fertility Table 1: Distribution of ever-married women aged 15-49 years, by age

\begin{tabular}{lrr}
\hline $\begin{array}{l}\text { Age groups } \\
\text { (in years) }\end{array}$ & Number & Percent \\
\hline $15-19$ & 27 & 4.8 \\
$20-24$ & 113 & 20.3 \\
$25-29$ & 132 & 23.7 \\
$30-34$ & 122 & 21.9 \\
$35-39$ & 80 & 14.3 \\
$40-44$ & 41 & 7.3 \\
$45-49$ & 43 & 7.7 \\
\hline Total & 558 & 100.0 \\
\hline
\end{tabular}

Rate (GFR), Age Specific Fertility Rate (ASFR) and Total Fertility Rate (TFR), calculated for 'past one year', are presented here. A look at the current fertility levels indicates that CBR for Gujjars of Delhi is 19.30 births per 1,000 individuals. It is higher than all Delhi crude birth rate for year 2002 (17.2: SRS, 2003), but lower than that of all India (25.0: SRS, 2003). GFR is estimated at 66.44 births per 1000 women. The value for TFR is obtained as 1.76 births per woman while Gross Reproduction Rate (GRR) 
that suggests how effectively mothers are replacing themselves with daughters who would bear the next generation is 0.83 female births per woman for Gujjars. The estimates of ASFRs show that majority of total fertility is concentrated in the prime childbearing ages of 20-29 years (Fig. 1). The fertility rate declines substantially in the next age group 30-34 years. Among Gujjar women, early childbearing (at the age of 15-19 years) and child bearing at the age of 30 years and above is quite low, during one year preceding the study.

Age at First marriage and Cohabitation: In the present study age at first marriage refers to age at formal marriage. In Gujjars, the formal marriage is not always immediately followed by cohabitation particularly if marriage occurs at a

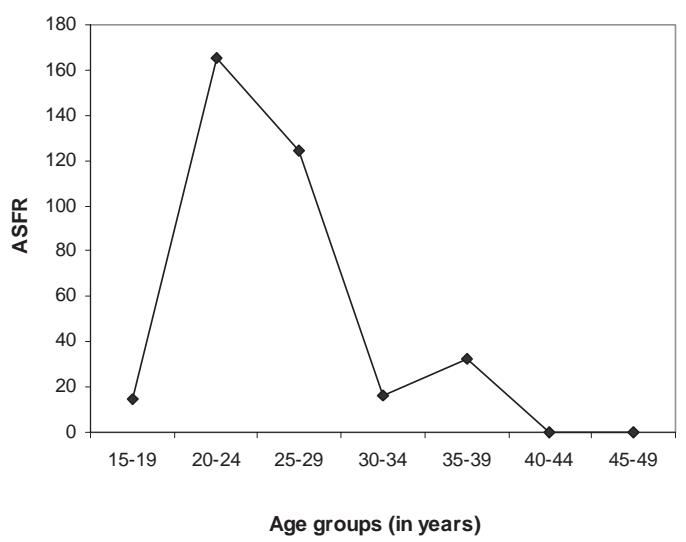

Fig. 1. Age-specific fertility rates (during one year period prior to the study)

very young age. Rather, cohabitation typically begins only after the 'Gauna' ceremony. The study of patterns of age at first marriage indicates that more than three-fourth of the women got married between 15-19 years of age while proportion marrying before 15 years of age and after 20 years of age is low (Table 2A). It is

Table 2A: Percent distribution of ever-married women aged 15-49 years, by age at first marriage

\begin{tabular}{lcc}
\hline $\begin{array}{l}\text { Age at } \\
\text { marriage }\end{array}$ & Number & Percent \\
\hline $10-14$ & 59 & 10.57 \\
$15-19$ & 434 & 77.78 \\
$20-24$ & 63 & 11.29 \\
$>24$ & 2 & 0.36 \\
\hline Total & 558 & 100.00 \\
\hline
\end{tabular}

observed that three-fifth of the women got married before reaching 18 years of age (Table 2B). The median age at first marriage for women aged 15-49 years is 17 years (mean 17.05 years).

Age at cohabitation (considered in the study as, age at consummation of marriage/ age at effective marriage) is relevant for fertility studies as it determines the reproductively active period of a woman and has a direct bearing on fertility. More than four-fifth of the women, started cohabiting with their husband between 15-19 years of age (Table 3A). It is observed that more than half of the women started cohabitation between 18-20 years of age (Table 3B).

The median age at first cohabitation with husband is 18 years (mean 17.82 years) for women aged 15-49 years indicating a median gap of 12 months between age at marriage and age at cohabitation. The mean age at effective marriage for females among Gujjars is 17.82 years which is lower than the mean age at effective marriage for females 15 years and above (19.3: SRS, 1999) and slightly below the legal permissible age. This may be due to lower

Table 2B: Percent distribution of ever-married women aged 15-49 years, by age at first marriage

\begin{tabular}{lcc}
\hline $\begin{array}{l}\text { Age at } \\
\text { marriage }\end{array}$ & Number & Percent \\
\hline$<18$ & & \\
$18-20$ & 181 & 61.11 \\
$>20$ & 28 & 33.87 \\
Total & 558 & 5.02 \\
\hline
\end{tabular}

Table 3A: Percent distribution of ever-married women aged 15-49 years, by age at cohabitation

\begin{tabular}{lrr}
\hline $\begin{array}{l}\text { Age at } \\
\text { cohabitation }\end{array}$ & Number & Percent \\
\hline $10-14$ & 12 & 2.15 \\
$15-19$ & 481 & 86.20 \\
$20-24$ & 63 & 11.29 \\
$>24$ & 2 & 0.36 \\
\hline Total & 558 & 100.00
\end{tabular}

Table 3B: Percent distribution of ever-married women

\begin{tabular}{lcc} 
& aged 15-49 years, by age at cohabitation \\
\hline $\begin{array}{l}\text { Age at } \\
\text { cohabitation }\end{array}$ & Number & Percent \\
\hline$<18$ & & \\
$18-20$ & 219 & 39.25 \\
$>20$ & 311 & 55.73 \\
Total & 28 & 5.02 \\
\hline
\end{tabular}


women's status besides parent's education and attitude among Gujjars; as parent's education, religion, family type, age at menarche, female education, are some of the factors associated with female age at marriage (Srivastava, 1984; Rao and Sureender, 1998).

Reproductive Wastage: Reproductive wastage includes still births, spontaneous and induced abortions. Of the 2023 pregnancies reported by sampled women only small proportion of abortions and still births were reported (Table 4).

There is relatively little variation in the outcome of pregnancies by age except for the age group 15-20 years, where the combined percentage of abortions and stillbirths is relatively high, which is in acceptance to the findings that risk of pregnancy, besides older mother, is highest at young child bearing ages, as younger mothers i.e., below 20 years, are not physiologically completely prepared for the

Table 4: Percent distribution of all pregnancies of evermarried women aged 15-49 years, by pregnancy outcome and age of women

\begin{tabular}{lrrrrrr}
\hline $\begin{array}{l}\text { Age } \\
\text { (in } \begin{array}{c}\text { Spon- } \\
\text { years) }\end{array}\end{array}$ & $\begin{array}{c}\text { taneous } \\
\text { abor- } \\
\text { tions }\end{array}$ & $\begin{array}{c}\text { ced } \\
\text { abor- } \\
\text { tions }\end{array}$ & $\begin{array}{c}\text { Still- } \\
\text { births }\end{array}$ & $\begin{array}{c}\text { Live } \\
\text { births }\end{array}$ & $\begin{array}{c}\text { Total } \\
\text { per- } \\
\text { cent }\end{array}$ & $\begin{array}{c}\text { Num- } \\
\text { ber } \\
\text { of } \\
\text { preg- } \\
\text { nancies }\end{array}$ \\
\hline $15-19$ & 22.2 & 11.1 & - & 66.7 & 100.0 & 9 \\
$20-24$ & 8.9 & 4.2 & 0.5 & 86.3 & 100.0 & 190 \\
$25-29$ & 9.5 & 4.0 & 3.8 & 82.7 & 100.0 & 451 \\
$30-34$ & 10.0 & 2.0 & 2.9 & 85.2 & 100.0 & 512 \\
$35-39$ & 6.4 & 2.2 & 2.8 & 88.6 & 100.0 & 361 \\
$40-44$ & 8.4 & 1.0 & 2.0 & 88.7 & 100.0 & 203 \\
$45-49$ & 8.4 & 3.0 & 4.4 & 84.2 & 100.0 & 297 \\
\hline Total & 8.8 & 2.8 & 3.0 & 85.5 & 100.0 & 2023 \\
\hline
\end{tabular}

process of reproduction (Montagu, 1963). There were 3.2 induced abortions and 3.5 stillbirths for every 100 live births among Gujjars of Delhi. Majority of pregnancies resulted in live births (85.5 percent) as compared to reproductive loss. Number of Children Ever-born and Living: The number of children a woman has ever born, is a cohort measure of fertility as compared to period measure of fertility like crude birth rate, age specific fertility rate, etc. as it reflects the experience of groups of women over a number of years rather than a specific calendar year (Weeks, 2002). The interaction of maternal age and parity (i.e. birth order) is of interest as younger mother are at risk of pregnancy wastage and babies of older mother are at risk of congenital malformations. Also, the frequency of mortality increases considerably with higher order of birth. Ever-married Gujjar women in the childbearing years have borne an average of 3.34 children and have 3.10 currently living i.e., for over three children born around ninety percent are surviving (Table 5).

The mean number of children ever born increases steadily with age, reaching a high of over five children per woman for the 45-49 age group. More than one-fifth of the women in the age group of 15-19 years have ever had a child reflecting the past pattern of relatively early marriage and teenage childbearing. The distribution of women aged 45-49 years by number of children ever born is important because these women have nearly completed their childbearing. Thus, the distribution of ever born represents the completed parity distribution for this cohort of women. Results indicate that women who were born before 1960s have higher

Table 5: Percent distribution of ever-married women aged 15-49 years, by number of children ever born and mean number of children ever born and living, according to age

\begin{tabular}{|c|c|c|c|c|c|c|c|c|c|c|c|c|c|}
\hline \multirow{2}{*}{$\begin{array}{l}\text { Age } \\
\text { (in } \\
\text { (years) }\end{array}$} & \multicolumn{9}{|c|}{ Children ever born } & \multirow{2}{*}{$\begin{array}{c}\text { Total } \\
\text { percent }\end{array}$} & \multirow{2}{*}{$\begin{array}{c}\text { Number } \\
\text { of } \\
\text { women }\end{array}$} & \multirow{2}{*}{$\begin{array}{l}\text { Mean } \\
C E B^{*}\end{array}$} & \multirow{2}{*}{$\begin{array}{l}\text { Mean } \\
\text { children } \\
\text { living }\end{array}$} \\
\hline & 0 & 1 & 2 & 3 & 4 & 5 & 6 & 7 & $8+$ & & & & \\
\hline $15-19$ & 77.8 & 22.2 & - & - & - & - & - & - & - & 100.0 & 27 & 1.0 & 0.8 \\
\hline $20-24$ & 15.9 & 35.4 & 38.1 & 8.8 & 1.8 & - & - & - & - & 100.0 & 113 & 1.7 & 1.6 \\
\hline $25-29$ & 1.5 & 2.3 & 31.8 & 45.5 & 15.9 & 2.3 & - & 0.8 & - & 100.0 & 132 & 2.9 & 2.7 \\
\hline $30-34$ & - & 3.3 & 11.5 & 35.2 & 31.1 & 13.9 & 4.1 & - & 0.8 & 100.0 & 122 & 3.6 & 3.4 \\
\hline $35-39$ & - & - & 8.8 & 33.8 & 31.3 & 7.5 & 13.8 & 3.8 & 1.3 & 100.0 & 80 & 4.0 & 3.7 \\
\hline $40-44$ & - & - & 4.9 & 22.0 & 29.3 & 26.8 & 7.3 & 9.8 & - & 100.0 & 41 & 4.4 & 4.0 \\
\hline $45-49$ & - & - & 2.3 & 2.3 & 16.3 & 18.6 & 25.6 & 20.9 & 14.0 & 100.0 & 43 & 5.8 & 5.3 \\
\hline Total & 7.3 & 9.5 & 19.5 & 26.9 & 18.8 & 8.1 & 5.4 & 3.0 & 1.4 & 100.0 & 558 & 3.34 & 3.10 \\
\hline S.D & - & - & - & - & - & - & - & - & - & - & - & 1.58 & 1.42 \\
\hline
\end{tabular}

* CEB refers to children ever born 
fertility than the younger women. It is to be recalled that no births have occurred in this age group during the last one year. One-fourth of the women are at parity six which is higher than the mean number of children ever born of over five (Table 5). Nil childlessness in the older age groups suggests the absence of primary infertility among Gujjars of Delhi. For all the women aged 15-49 years the average number of children who died is 0.24 per women. Overall, infant and child mortality is relatively high in groups where fertility is high.

Age of Mothers at First and Last Birth: The onset and cessation of childbearing is important demographic indicator of fertility. Early births are not uncommon for ever married Gujjar women in the age group 15-19 years (Table 6). More than one-fifth of women aged 15-19 years have given birth to children indicating teenage childbearing. Over half of the women in the age group 45-49 years have had their first childbirth before the age of 20 years, while the corresponding proportion of such women in the age group 20-24 years is two-fifth indicating decline in early childbearing (before the age of 20 years) during last two and half decades. The median age at first birth is marginally higher for younger women. Overall, the median age at first birth is 19 years (mean 19.59 years) for Gujjar women aged 15-49 years indicating relatively early marriage and childbearing.

The age at last childbirth (for women aged 40-49 years) is an important demographic determinant of fertility. It is suggestive that childbearing is virtually complete by these ages. Four-fifth of the women had completed their childbearing by age 30 in the age group 40-44 years with median age at 26 years (Table 7 ).

The childbearing was completed by 30 years of age, for more than half women in age group 45-49 years, with 29 years as median age at last childbirth. No one reported having a birth after age 39 years indicating that generally childbearing is complete by this age. Generally speaking, Gujjar women are reproductively active during prime childbearing ages of 19 to 29 years.

Postpartum Amenorrhoea: The duration of postpartum amenorrhoea following a birth is closely associated with the duration of breastfeeding, which tends to suppress resumption of ovulation (Huffman et al., 1987; Srinivasan et al., 1989; Babu, 1996). Thus, lactational amenorrhoea or the postpartum amenorrhoea is one of the factors that influence the risk of pregnancy following a birth. Over 90 percent of the women, based on cross-sectional data, who had a birth in the three months period prior to the study were amenorrhoeic while more than two-third of women whose last birth occurred 4-5 months prior to the study, were amenorrhoeic mother (Table 8). The proportion of amenorrhoeic mothers gradually decreases as the number of months since birth increases. The proportion of women still amenorrhoeic at 8-9 months since birth is about one-fourth. The

Table 6: Percent distribution of ever married women aged 15-49 years, by age at first child birth and age

\begin{tabular}{|c|c|c|c|c|c|c|c|c|c|}
\hline \multirow{2}{*}{$\begin{array}{l}\text { Mother's age } \\
\text { (in years) }\end{array}$} & \multirow[b]{2}{*}{ No birth } & \multicolumn{5}{|c|}{ Age at first birth } & \multicolumn{2}{|c|}{ Total } & \multirow{2}{*}{$\begin{array}{l}\text { Median } \\
\text { age at } \\
\text { first birth }\end{array}$} \\
\hline & & $<18$ & $18-19$ & $20-21$ & $22-24$ & $25+$ & Percent & $\begin{array}{l}\text { Num- } \\
\text { ber }\end{array}$ & \\
\hline $15-19$ & 77.8 & 14.8 & 7.4 & - & - & - & 100.0 & 27 & $\mathrm{NC}^{*}$ \\
\hline $20-24$ & 15.9 & 3.5 & 36.3 & 34.5 & 9.7 & - & 100.0 & 113 & 19.5 \\
\hline $25-29$ & 1.5 & 9.1 & 36.4 & 35.6 & 16.7 & 0.8 & 100.0 & 132 & 19.5 \\
\hline $30-34$ & - & 13.1 & 45.1 & 27.9 & 11.5 & 2.5 & 100.0 & 122 & 19.0 \\
\hline $35-39$ & - & 17.5 & 41.3 & 25.0 & 8.8 & 7.5 & 100.0 & 80 & 19.0 \\
\hline $40-44$ & - & 2.4 & 43.9 & 26.8 & 22.0 & 4.9 & 100.0 & 41 & 20.0 \\
\hline $45-49$ & - & 30.2 & 23.3 & 18.6 & 25.6 & 2.3 & 100.0 & 43 & 19.0 \\
\hline
\end{tabular}

NC* Not calculated because less than 50 percent of women have had a first child birth

Table 7: Percent distribution of ever married women aged 40-49 years, by age at last child birth and age

\begin{tabular}{|c|c|c|c|c|c|c|c|c|}
\hline \multirow{2}{*}{$\begin{array}{l}\text { Mother's age } \\
\text { (in years) }\end{array}$} & \multicolumn{4}{|c|}{ Age at last birth } & & \multicolumn{2}{|c|}{ Total } & \multirow{2}{*}{$\begin{array}{l}\text { Median age at } \\
\quad \text { last birth }\end{array}$} \\
\hline & $<25$ & $25-29$ & $30-34$ & $35-39$ & $40+$ & Percent & Number & \\
\hline $40-44$ & 22.0 & 58.5 & 14.6 & 4.9 & - & 100.0 & 41 & 26 \\
\hline $45-49$ & 7.0 & 48.8 & 37.2 & 7.0 & - & 100.0 & 43 & 29 \\
\hline
\end{tabular}


median and mean duration of postpartum amenorrhoea are 4.5 and 4.9 months respectively, indicating that Gujjar women remain insusceptible to pregnancy for over 4 months after birth due to the effect of postpartum amenorrhoea. Breastfeeding is the major determinant of prolonged postpartum amenorrhoea, the birth interval and the resumption of next menses, in societies where it is universal (like in the present Gujjar population), prolonged and of high intensity (Singh and Negi, 1985; Srinivasan et al., 1989; Babu, 1996). However, duration of postpartum amenorrhoea varies from women to women (Knodel and Lewis, 1984; Jones, 1988).

Age at Menarche and Menopause: Menarche is the primary indicator of onset of sexual maturation in a female which affects her reproductive life. Age at menarche is varied as it being physiological phenomenon is affected by interaction between different factors such as genetic, nutrition, and socio-economic status (Eveleth and Tanner, 1976). Earlier, in India, age at menarche in many societies also determined age at marriage, as girls were married before or immediately after the attainment of menarche (Mandelbaum, 1974). Early menarche and late menopause gives greater reproductive span than vice-versa situation, therefore, higher fertility is expected in such cases. Among Gujjars, menarche is relatively uncommon before 13 years of age (Table 9). Menarcheal age for ever-married women ranges between 11 and 18 years. The median age at menarche is 14.0 years (mean age at menarche is 13.99 years). The mean menarcheal age is almost same as that for rural Indian population (mean 14.04 years: ICMR, 1972).

Another factor limiting fertility is the onset

Table 8: Percentage of babies born during the past one year whose mothers are postpartum amenorrhoeic, by number of months since birth

\begin{tabular}{lccc}
\hline $\begin{array}{l}\text { Months } \\
\text { since } \\
\text { birth }\end{array}$ & $\begin{array}{c}\text { Total } \\
\text { number of } \\
\text { births }\end{array}$ & $\begin{array}{c}\text { Babies whose mothers } \\
\text { are postpartum } \\
\text { amenorrhoeic }\end{array}$ \\
\cline { 2 - 4 } & & Percent & Number \\
\hline $0-3$ & 12 & 91.7 & 11 \\
$4-5$ & 10 & 70.0 & 7 \\
$6-7$ & 14 & 50.0 & 7 \\
$8-9$ & 18 & 27.8 & 5 \\
$10-11$ & 14 & - & - \\
\hline Total & 68 & 44.1 & 30 \\
\hline
\end{tabular}

of menopause (women who are pregnant or postpartum amenorrhoeic are considered not to be menopausal). After 30 years of age, the risk of pregnancy begins to decline with age, as an increasing proportion of women become infecund. Menopause is relatively infrequent before the age of 42 years and after 46 years (Table $10)$.

Menopausal age for ever-married women ranges between 41 and 48 years, while the mean menopausal age is 44.06 years (median age : 44 years). Like age at menarche, age at menopause too is affected by factors like nutrition, genetic, socio-economic status, environmental conditions, etc (Frisch and McArthur, 1974; Beall, 1983; ICMR, 1998).

Current Mortality Rates: Mortality rates of Gujjars in past one year estimated on the basis of Crude Death Rate (CDR), Infant Mortality Rate (IMR) and Cause Specific Death Rate (CSDR) are presented here. Such information is relevant both to demographic assessment of the population and to health policies and programmes. Mortality checks the unlimited growth of population and regulates the distribution of individuals in different age groups. It is a continuous force of attrition tending to reduce population but having its effect

Table 9: Percent distribution of ever-married women aged 15-49 years, by age at menarche

\begin{tabular}{lcc}
\hline \multirow{2}{*}{ Age at menarche } & \multicolumn{2}{c}{ Frequency } \\
\cline { 2 - 3 } & Number & Percent \\
\hline$<11$ & 0 & 0.0 \\
$11-12$ & 30 & 5.4 \\
$13-14$ & 357 & 64.0 \\
$15-16$ & 169 & 30.3 \\
$17-18$ & 2 & 0.4 \\
\hline Total & 558 & 100.0 \\
\hline
\end{tabular}

Table 10: Percent distribution of ever-married women aged 15-49 years, who are menopausal, by age at menopause

\begin{tabular}{lcc}
\hline Age at menopause & \multicolumn{2}{c}{ Frequency } \\
\cline { 2 - 3 } & Number & Percent \\
\hline$<40$ & 0 & 0.0 \\
$41-42$ & 9 & 17.0 \\
$43-44$ & 25 & 47.2 \\
$45-46$ & 14 & 26.4 \\
$47-48$ & 5 & 9.4 \\
\hline Total & 53 & 100.0 \\
\hline
\end{tabular}


counteracted by the force of fertility. In effective reduction of mortality level, infant mortality has a key role to play.

Crude Death Rate for Gujjars of Delhi is 5.96 per 1,000 population which is slightly higher than all Delhi crude death rate for year 2002 (5.1: SRS, 2003) but lower than that of all India (8.1: SRS, 2003). The infant mortality rate is used internationally as a reliable indicator of health of children and level of development of socio-economic status and quality of life. Among Gujjars infant mortality rate (29.41 per 1000 live births) is not only lower than that for all Delhi population (32.0: SRS, 2003), but much lower than that for all India (64.0: SRS, 2003). This is probably due to better standard of living, hygiene condition, access to health facilities, and improving educational levels.

Evaluation of death rates by cause of death indicates that respiratory disorders such as T.B., pneumonia are the major cause of death among Gujjars (Table 11). Cause specific death rate due to respiratory disorders is 1.70 deaths per 1000 population. Death rates due to other causes such as fever, accidents, diseases of circulatory system and digestive disorders are in varying proportion with digestive disorders being the least common cause of death.

In India, significant proportion of deaths occur during $0-4$ years $(32.7 \%)$ and old age (60 years and above, 35.5\%: RGI, 1995). Though during the last 50 years IMR of India has come down by more than $50 \%$, but it is still very high as compared with the developed countries of the world like USA, UK, Japan and France. As mentioned earlier among Gujjars, infant and child mortality is relatively higher in groups where fertility is higher. This supports the argument that increased mortality is response to high fertility (Chen et al., 1974; Choudhury et al., 1976). Another relationship is also well

Table 11: Cause specific death rates (during the one-year period prior to the study)

\begin{tabular}{lcc}
\hline Cause of death & $\begin{array}{c}\text { Number of } \\
\text { deaths }\end{array}$ & $\begin{array}{c}\text { Cause specific } \\
\text { deaths rates }\end{array}$ \\
\hline Accidents and injuries & 3 & 0.85 \\
Fever & 5 & 1.42 \\
Coughs (disorder of & & \\
$\quad$ respiratory system) & 6 & 1.70 \\
Diseases of circulatory sys. & 5 & 1.42 \\
Digestive disorders & 2 & 0.57 \\
\hline Total & 21 & 5.96 \\
\hline
\end{tabular}

recognized i.e., high fertility is a biological and behavioural response to high mortality (Preston, 1978). In single terms higher infant mortality tends to higher fertility and vice-a-versa.

\section{CONCLUSIONS}

From the foregoing discussion, it may be concluded that in general, the egos are currently married, less educated and engaged in household activities. Fertility among Gujjars is higher than all Delhi population as indicated by period and cohort measures of fertility as well as by lower mean age at effective marriage for females. Gujjar women are by and large reproductively active during prime childbearing ages of 20-29 years. Gujjar women tend to marry early and there is still a fair amount of fertility at very younger ages. Older women are more likely than younger women to have married at an early age. Majority of pregnancies resulted in live births. For over three children born, around ninety percent are surviving. Infant and child mortality is relatively higher in groups where fertility is higher, reflecting a well recognized fertility-mortality relationship. The mean duration of postpartum amenorrhoea is 4.9 months. Mean age at menarche is 13.99 years while mean menopausal age is 44.06 years. Though IMR is lower among Gujjars, but overall mortality (CDR) is slightly higher than all Delhi population with respiratory disorder being the primary cause of death.

\section{ACKNOWLEDGEMENT}

The authors are grateful to the families who form the basis of present study without whose co-operation and kind help, this work would not have been so smoothly possible.

\section{REFERENCES}

Agarwala, S.N.: Effect of a rise in female age at marriage on birth rate in India, In: Proceedings of the World Population Conference, Belgrade (1967).

Babu.K.S: The influence of traditional occupation on breastfeeding pattern. Man in India, 76(3): 267-272 (1996).

Basu, S.K., Kshatriya, G.K and Jindal, A.: Fertility and mortality differentials among the tribal population groups of Bastar district Madhya Pradesh. Human Biology, 60: 407-416 (1988).

Beall, C.M.: Age at Menopause and Menarche in a High Altitude Himalayan population. Annals of Human 
Biology, 10 (4): 365-370 (1983).

Bhasin, M.K and Nag, Shampa: A demographic profile of Jammu and Kashmir: Population Structure. Journal of Human Ecology, 13: 1-55 (2002a).

Bhasin, M.K and Nag, Shampa: A demographic profile of Jammu and Kashmir: Estimates, trends and differential in fertility behaviour. Journal of Human Ecology, 13: 57 112 (2002b).

Bhasin, V.: Habitat, Habitation and Health in the Himalayas. Kamla-Raj Enterprises, Delhi (1990).

Bhuyan, K.C. and Ahmed, M.U.: Fertility and family planning practices in rural Bangladesh. The Journal of Family Welfare, 30(3): 57-70 (1984).

Chen, L.S., Ahmed, M.G. and Mosley, W.H.: A Prospective study of birth interval dynamics in rural Bangladesh. Population Studies, 28(2): 277-279 (1974).

Choudhury, R.H., Khan, A.R. and Chen, L.S.: The effect of child mortality experience on subsequent fertility: Pakistan and Bangladesh. Population Studies, 30(2): 249-262 (1976).

Choudhury, R.H.: The influence of female education, labor force participation, and age at marriage on fertility behavior in Bangladesh. Social Biology, 31: 59-73 (1984).

Dabral and Malik: Demography study of Gujjars of Delhi: Population structure and socio-cultural profile. Journal of Human Ecology: 16(1): 17-24 (2004a).

Durch, J.A.: Nuptiality Patterns in Developing Countries Implications of Fertility. Population Reference Bureau, Washington (1980).

Elamin,M.A. and Bhuyan,K.C.: Differential fertility in north eastern Libya. The Journal of Family Welfare, 45(1): 1222 (1999).

Eveleth, P.B. and Tanner, J.M.: Worldwide Variation in Human Growth. Cambridge University Press, Cambridge (1976).

Frisch, R.E. and McArthur, J.M.: Menstrual cycles: Fatness as a determinant of minimum weight for height necessary for their maintenance or onset. Science, 185: 949-951 (1974).

Huffman, S.L., Ford, K., Alien, H.A. Jr. and Streble, P.: Nutrition and Fertility in Bangladesh: Breastfeeding and Postpartum Amenorrhoea. Population Studies, 41: 447-462 (1987).

Indian Council of Medical Research-I.C.M.R.: Growth and Physical Development of Indian Infants and Children. Indian Council of Medical Research, New Delhi (1972).

Indian Council of Medical Research-I.C.M.R: Menopause and HRT. I.C.M.R Bulletin, 28(1): 1-7 (1998).

Jones, R.E.: A bio-behavioral model for breastfeeding effects on return to menses postpartum in Javanese Women. Social Biology, 35: 307-322 (1988).

Knodel, John and Lewis, Gary: Postpartum amenorrhea in selected developing countries: Estimates from Contraceptive Prevalence Surveys. Social Biology, 31: 309-319 (1984)

Kshatriya, G.K., Singh, P. and Basu, S.K.: Anthropodemographic features and health care practices among the Jaunsaris of Jaunsar-Bawar, Dehradun, Uttar Pradesh. Journal of Human Ecology, 8: 347-354 (1997).

Malik, S.L. and Hauspie, R.C.: Age at menarche among high altitude Bods of Ladakh (India). Human Biology, 58(4): 541-548 (1986).

Mandelbaum, D.G.: Human Fertility in India: Social
Components and Policy Perspectives. University of California Press, Berkeley (1974).

Maudlin, W.P. and Berelson, B.: Conditions of fertility decline in developing countries, 1965-1975. Studies in Family Planning, 9: 89-145 (1978).

Montagu, A.: Human Heredity. The New American Library of World Literature, New York (1963).

Nag, M.: Modernization and its Impact on Fertility: The Indian Scene (Working paper No, 84. Center for Policy Studies). The population Council, New York (1982).

NIHFW Report 1999-2000: National Institute of Health and Family Welfare. Department of Family Welfare, India.

Pandey, G.D. and Talwar, P.P.: Some aspects of marriage and fertility in rural Uttar Pradesh. Demography India, 16: 301-310 (1987).

Pandey, P.L., Jain, D.C., Pandey, G.D., Choubey, R. and Tiwary, R.S.: Some aspects of social factors affecting fertility behaviour of Gond Women. Man in India, $80(3$ and 4): 251-258 (2000)

Pawson, I.G.: Growth and development in high altitude populations: A Review of Ethiopian, Peruvian and Nepalese Studies. Proceedings of the Royal Society of London, B, 194: 83-98 (1976).

Preston, H.Samuel: The Effects of Infant and Child Mortality on Fertility. Academic Press, New York (1978).

Rao, G.R. and Sureender, S.: Factors associated with female age at marriage in Pondicherry. Demography India, 27: 401-418 (1998)

Registrar General and Census Commissioner, India: Fertility Differentials in India (1971).

RGI: Survey of Causes of Death (Rural) India, Annual Report. Office of Registrar General of India, New Delhi (1995).

RGI: Survey of Causes of Death (Rural) India, Annual Report. Office of Registrar General of India, New Delhi (1997).

Sample Registration System: SRS Statistical Report. Office of Registrar General of India, New Delhi (1999).

Singh, V.K. and Negi, K.S.: An investigation into relationship between breastfeeding and amenorrhoea, In: Principles and Practice of Statistics in Medicine, R.N. Srivastava, B.L.Verma and G.D.Shukla (Eds.). H.P., House, New Delhi (1985).

Srinivasan, K., Pathak, K.B. and Pandey, A.: Determinants of breast feeding and post-partum amenorrhoea in Orissa. Journal of Biosocial Science, 21(3): 365-371 (1989).

Srivastava, J.N.: Determinants of female age at marriage in rural Uttar Pradesh. Analytical Report 30. Population Research Centre, Lucknow (1984).

SRS: Sample Registration system Bulletin: Provisional estimates of birth rates, death rates, natural growth rate and infant mortality, 2002. Office of Registrar General of India, New Delhi (2003).

Thompson, W.S. and Lewis, D.T.: Population Problems. McGraw Hill Publishing Co., New Delhi (1965).

Verma, Arvind: Socio-cultural correlates of infant mortality in a primitive tribe. Journal of Human Ecology, 13: 203207 (2002).

Weeks, John, R.: Population: An Introduction to Concepts and Issues, $8^{\text {th }}$ Ed. Wadsworth Thomson learning, U.S.A (2002).

Yadav,S.S. and Badari,V.S.: Age at effective marriage and fertility: An analysis of data for North Kanara. The Journal of Family Welfare, 43(3): 61-66 (1997). 